\title{
A emergência do sujeito participativo: interseções entre ciência, política e ontologia
}

\author{
João Arriscado Nunes* \\ Daniel Neves da Costa* \\ António Carvalho* \\ Ana Raquel Matos*
}

\section{Resumo}

Nas últimas décadas, os dispositivos de participação pública têm registado um crescimento exponencial. Estes procedimentos podem assumir uma diversidade de configurações, gerando um número de questões teóricas e práticas. A partir da análise de dois estudos de caso - grupos de discussão sobre nanotecnologias em Coimbra, Portugal, e Conselhos de Saúde em Belo Horizonte, Brasil - este artigo oferece uma reflexão sobre as questões políticas e metodológicas relacionadas com a conceção e implementação de procedimentos participativos. A análise explora a emergência do cidadão participativo, associado a capacidades e formas de conhecimento que permitem a intervenção em espaços deliberativos. Argumenta-se que os dispositivos participativos e os processos de subjetivação estão interligados, dialogando-se com as reflexões de Foucault sobre subjetividade e com abordagens pós-humanistas no âmbito dos Estudos Sociais de Ciência e Tecnologia. Os dois estudos de caso ilustram como os procedimentos participativos geram novas capacidades epistémicas, retóricas e normativas associadas à habilitação e subjetivação dos participantes. Dessa forma, o artigo explora os aspetos políticos das práticas, metodologias e processos que suportam o envolvimento de cidadãos em ciência, tecnologia e saúde, contribuindo para a desnaturalização do sujeito participativo e para o reconhecimento da dimensão performativa das ciências sociais.

Palavras-chave: Participação pública em Ciência e Tecnologia, Viragem ontológica, Estudos Sociais de Ciência e Tecnologia, Nanotecnologias, Conselhos de Saúde

*Centro de Estudos Sociais da Universidade de Coimbra. Coimbra, Portugal. 


\section{The emergence of a participatory subject: intersections between science, politics and ontology}

\section{Abstract}

Over the last few decades, there has been a proliferation of devices of public participation. Those procedures can assume a wide range of configurations, generating a number of practical and theoretical issues. Drawing upon the analysis of two case studies - focus groups on nanotechnologies in Coimbra, Portugal, and Health Councils in Belo Horizonte, Brazil - this article reflects on political and methodological issues related to the conception and implementation of participatory devices. Our analysis explores the emergence of the participatory subject, intertwined with abilities and forms of knowledge that allow intervention in deliberative spaces. It is argued that participatory devices and subjectification processes are intertwined, following Foucault's reflections on subjectivity and post-humanist approaches within Science and Technology Studies. The two case studies illustrate how participatory processes trigger new epistemic, rhetorical and normative capacities linked to the habilitation and subjectification of participants. In that sense, the article explores the political aspects of practices, methodologies and processes that support public engagement with science, technology and health, leading to the denaturalization of the participatory subject and to the recognition of the performative dimension of social sciences.

Keywords: Public participation in Science and Technology, Ontological turn, Social Studies of Science and Technology, Nanotechnologies, Health Councils.

\section{Introdução'}

as últimas décadas, temos assistido à proliferação de experiências
institucionais de cariz participativo. O número, complexidade
e diversidade de contextos institucionais e políticos onde são testadas e implementadas têm vindo a suscitar interesse e debate académicos (Rowe; Frewer, 2000).

As configurações destes procedimentos participativos são diversas, desde Orçamentos Participativos, Conferências de Consenso, Júris de Cidadãos,

\footnotetext{
${ }^{1}$ Devido ao contexto geográfico dos autores, este artigo encontra-se redigido em português
} de Portugal, ao abrigo do Acordo Ortográfico de 1990. 
Conselhos de Políticas Setoriais, Eventos Deliberativos e Grupos de Discussão (Rowe; Frewer, 2005). As questões que levantam são inúmeras e a vários níveis, designadamente: características burocrático-institucionais; os projetos políticos que promovem; implicações na governação em múltiplas escalas (local, regional, nacional) e setores (território, ambiente, saúde, ciência etc.); potencial inclusivo e emancipatório que comportam; relação entre leigos e peritos; impactos na produção de públicos e de novos coletivos; relação entre democracia representativa e participativa (Carvalho; Nunes, 2013). A estes dispositivos são ainda atribuídas limitações e fragilidades em torno de questões de representatividade ou do perigo de manipulação e cooptação (Carvalho; Nunes, 2014).

O caso particular do trabalho desenvolvido no âmbito dos Estudos Sociais de Ciência e Tecnologia (ESCT) tem elucidado acerca de como estes dispositivos "performam" os seus distintos públicos (Wynne et al., 2007), realçando aspetos materiais e metodológicos. Noções como política ontológica (Mol, 1999) salientam a dimensão performativa da realidade, cuja emergência é mediada por práticas, associações e não humanos, com fortes implicações na forma como se concebe a subjetividade humana (Carvalho, 2017).

As metodologias das Ciências Sociais são consideradas performativas e com uma dimensão ontológica (Law, 2004; Callon, 1998; Callon, 2006). Quando economistas "constroem mercados", ou quando sociólogos e antropólogos lidam com públicos, está em causa não só a representação de uma realidade "exterior", mas o recrutamento de entidades que constituem objetos - mercados, coletivos, públicos etc. -, sublinhando a dimensão política destas disciplinas e práticas (Carvalho; Nunes, 2013).

Inspirados pela "viragem ontológica" nos ESCT (Woolgar; Lezaun, 2013; Jensen et al., 2017) procuramos, a partir de dois estudos de caso - grupos de discussão sobre nanotecnologias em Coimbra, Portugal, e Conselhos de Saúde em Belo Horizonte, Brasil -, refletir sobre as dimensões político-metodológicas associadas ao desenho e realização de procedimentos participativos. Por um lado, os grupos de discussão sobre nanotecnologias 
permitem-nos analisar como as aspirações públicas, visões e imaginários sociotécnicos (Jasanoff; Kim, 2009; Santos Pereira et al., 2017) sobre tecnologias promissoras emergem em função de intervenções dos cientistas sociais e de certas escolhas materiais e metodológicas. Por outro lado, os Conselhos de Saúde de Belo Horizonte exemplificam como os processos de educação permanente permitem aos conselheiros adquirir as ferramentas necessárias para que a sua ação tenha um impacto real na prestação de cuidados de saúde, representando os cidadãos de forma fidedigna. Em ambos os casos, estamos perante agenciamentos que requerem o desenvolvimento de novas capacidades que permitam aos sujeitos agir e participar de uma forma legítima, enquanto representantes de coletivos diretamente afetados por políticas de saúde ou enquanto cidadãos potencialmente afetados por novas inovações tecnológicas. Estas diferenças contribuem para o nosso argumento, permitindo-nos analisar como os espaços participativos levam a cabo formas de subjetivação que suportam a cidadania política e tecnológica, através de diversas mediações que incluem opções metodológicas, dispositivos espaciais, epistemológicos e não humanos.

Em ambos os estudos de caso, regista-se que a emergência do sujeito participativo está associada a uma subjetividade "equipada" com as competências que lhe permitem intervir em espaços de participação e deliberação. É através de uma multiplicidade de dispositivos, encarados enquanto tecnologias do sujeito (Foucault, 1988), que emerge um cidadão capaz de tomar decisões e emitir opiniões situadas e enunciados éticos, sociais e políticos, traduzindo os seus problemas e necessidades particulares em questões legíveis e consideradas "legítimas" num processo coletivo de discussão e de decisão. Nesse sentido, o ethos do cidadão participativo é mediado pelos espaços de participação, dotando o sujeito de ferramentas retóricas, epistémicas, técnicas, normativas, políticas e materiais que possibilitam a ação participativa. 


\section{Participação política e subjetivação}

Os procedimentos participativos surgem simultaneamente como complemento aos processos de delegação e representação das democracias contemporâneas (Callon et al., 2009) e como resposta a uma dupla crise da democracia - a crise da legitimidade e governabilidade (Hardt; Negri, 2001; Santos, 2005). A sua implementação procura configurar uma nova legitimidade institucional com vista a responder à incapacidade das instituições governativas em representarem um conjunto emergente de novos movimentos e reivindicações sociais.

As experiências participativas funcionam como dispositivos de subjetivação (Foucault, 2001). O sujeito participativo emerge através do desenvolvimento de competências que o "equipam" a assumir uma voz ativa no dispositivo e a dar sentido à sua situação social e política². A dimensão performativa do sujeito participativo é uma questão política. Se, por um lado, estes dispositivos complementam a dupla delegação promovida pelas democracias representativas (Callon et al., 2009), atribuindo novos poderes aos cidadãos, por outro lado eles atuam através de políticas ontológicas que "fabricam" sujeitos através de diferentes opções associadas à condução, desenho e formato desses procedimentos.

\section{A performatividade do sujeito participativo}

Este artigo dialoga com correntes teóricas como a Teoria da Ação e Cognição Distribuídas (Hutchins, 1994) e a Teoria do Ator-Rede (Callon, 1986; Law; Hassard, 1999; Latour, 2005), aprofundando as propostas conceptuais sobre a performatividade da economia (Callon; Muniesa, 2003) e do Homo economicus (Callon, 2008).

Argumentamos que a emergência do sujeito participativo ocorre através de dispositivos compostos por atores humanos (moderadores, organizadores, participantes) e não humanos (discursos, documentos,

${ }^{2}$ Seguimos a leitura Foucaultiana da noção grega de paraskeue habitualmente traduzida por equipamento (Foucault, 2006; Rabinow, 2009). 
equipamentos de cálculo, legislação, modelos teóricos etc.), designados por "agenciamentos" - "configurações sociotécnicas quando consideradas do ponto de vista da sua capacidade de agir e de dar sentido à ação" (Callon; Muniesa, 2003, p. 13). A ação assume-se como uma propriedade coletiva proporcionada por agenciamentos sociotécnicos, distribuída por uma série de entidades, o que reforça a importância da materialidade nas danças de agência entre humanos e não humanos (Pickering, 1995).

A participação processa-se, assim, através de configurações específicas que mobilizam um conjunto de recursos ou equipamentos que autorizam ou "habilitam" para essa mesma participação (Nunes et al., 2009) - recursos materiais, tecnológicos, discursivos, argumentativos e normativos, conhecimentos técnicos e epistémicos e vários procedimentos. Estes recursos são mobilizados pelos sujeitos no âmbito dos agenciamentos participativos. É através deles que a sua ação ganha forma e a sua cognição e poder argumentativos são possibilitados e "autorizados". Estes "actantes" (Latour, 2005) assumem um papel ativo numa rede sociotécnica (Law, 1987), neste caso um dispositivo participativo, possibilitando ao sujeito transformar-se numa entidade "deliberativa", proporcionando-lhe as disposições necessárias. É através da incorporação destes equipamentos e da sua mobilização que os sujeitos desenvolvem as competências necessárias a uma prática participativa legítima, possibilitando-lhes definir necessidades, prioridades e projetos de ação.

\section{Entre a reabilitação e a habilitação}

O processo de aquisição de equipamentos para a participação pode ser enquadrado a partir de duas abordagens distintas. Aqui, a proposta de Callon (2008), influenciada pelo debate sobre indivíduos portadores de deficiência e políticas de integração, assume especial relevância. Essa proposta parte da ideia de que a deficiência não está localizada exclusivamente no indivíduo, derivando também de um desajustamento entre o indivíduo e a sociedade. Deste modo, as políticas de integração podem seguir dois caminhos diferentes: 1) um que atribui esse desajustamento ao indivíduo, 
intervindo exclusivamente na sua adaptação à sociedade; 2) outro que procura simultaneamente ajustar a sociedade aos indivíduos. O primeiro designa-se "política de prosthesis de disciplina" e o segundo "política interativa de habilitação". Em todo o caso, ambas procuram criar as condições que possibilitem ao indivíduo portador de uma deficiência criar e desenvolver os seus projetos, potenciando a sua total integração numa sociedade na qual se via marginalizado. A conceção do indivíduo como possuindo um duplo défice - político e científico (Callon et al., 2009) dificulta a sua participação numa tomada de decisão informada e viável. A transformação de cidadão leigo em sujeito participativo obriga, dessa forma, a uma capacitação capaz de mitigar desajustes técnicos e políticos, habilitando os cidadãos a participar.

As "políticas de prosthesis" procuram equipar o indivíduo com as ferramentas e as competências indispensáveis à superação dos seus défices. Partem, no entanto, de um tipo ideal de sujeito participativo, dotado de um conjunto de instrumentos políticos e técnicos, pré-requisitos legítimos para participar. Esta perspetiva corresponde a uma lógica de reabilitação do indivíduo, a quem são atribuídas próteses que lhe conferem capacidade de ação, ainda que de uma forma rígida e disciplinada (Callon, 2008). Registamos a semelhança com o modelo de educação bancária criticado por Paulo Freire (Freire, 1970), que encara os indivíduos enquanto recipientes vazios a serem preenchidos com os conteúdos adequados, reproduzindo o que habitualmente se designa como o modelo do deficit na compreensão pública da ciência (Jasanoff, 2005).

As "políticas de habilitação" configuram uma abordagem distinta. A ação sobre o desajustamento não se cinge exclusivamente aos indivíduos portadores do duplo défice, mas procura também transformar o agenciamento em que estes se inserem, moldando os procedimentos e os dispositivos de participação. Dessa forma, as políticas de habilitação promovem a emergência de novas possibilidades de ação (Callon, 2008), na linha da contraproposta de Paulo Freire de uma pedagogia da libertação e da autonomia (Freire, 2008). As políticas de habilitação reconhecem a 
necessidade de transformação do dispositivo de participação para dar resposta às diferentes capacidades e recursos dos sujeitos participativos, não excluindo a necessidade de lhes atribuir ferramentas que possibilitem maior autonomia e eficácia na sua ação. A possibilidade de transportar entidades, conhecimentos e saberes exteriores para o dispositivo, de modo a permitir práticas não incluídas no "guião" do agenciamento, é uma das características chave destas políticas participativas.

\section{Os grupos de discussão sobre nanotecnologias}

O primeiro estudo de caso diz respeito ao desenvolvimento do cidadão participativo no contexto de grupos de discussão sobre as implicações sociais e éticas das nanotecnologias. As nanotecnologias são tecnologias emergentes que dizem respeito à caracterização, desenho, produção e aplicação de sistemas, estruturas e dispositivos que apresentam novas propriedades (físicas, biológicas e químicas) através do controlo da forma e tamanho à escala nanométrica (Ebbesen et al., 2006). Como as nanotecnologias resultam de uma convergência entre diversas áreas científicas - incluindo a física, biologia, bioquímica molecular, informática, química e engenharia - são esperadas inovações significativas nessas áreas à medida que o controlo sobre os níveis atómicos e moleculares aumenta (Sweeney et al., 2003). Apesar de extremamente promissoras e de terem gerado um significativo investimento público (aproximadamente 10 biliões de dólares anuais, Brock, 2014), as nanotecnologias levantam também uma série de questões éticas, nomeadamente no que diz respeito à disseminação de novos riscos, perda de privacidade e alteração da condição humana.

Os grupos de discussão surgiram enquadrados no projeto DEEPEN ${ }^{3}$ e foram organizados pela equipa portuguesa do projeto. O projeto visava gerar formulações éticas em função de aplicações tecnológicas ainda pouco disseminadas na sociedade, constituindo, por isso, formas leigas de éticas

${ }^{3}$ DEEPEN - Deepening Ethical Engagement and Participation in Emerging Nanotechnologies (2006-2009), coordenado por João Arriscado Nunes, do Centro de Estudos Sociais da Universidade de Coimbra e financiado pela Comissão Europeia. 
antecipatórias (Brey, 2012), refletindo um vasto espectro de subjetividades coletivas, direta ou indiretamente afetadas pelas nanotecnologias.

O grupo um era constituído por membros de organizações de pacientes e o grupo dois por defensores de terapias alternativas e complementares. $\mathrm{O}$ grupo três incluía membros de organizações ligadas ao ambiente, justiça social e ação local e o grupo quatro era composto por indivíduos subdivididos em duas categorias: autonomia e agência e utilizadores confiantes em tecnologias.

O que havia em comum entre a maioria dos participantes era o seu desconhecimento em relação às nanotecnologias. O objetivo dos grupos de discussão não era a mera identificação de preocupações "éticas" sobre estas tecnologias, mas sim a "capacitação" ou "educação" dos participantes sobre nanotecnologias, até que desenvolvessem uma "conscientização" (Freire, 1970). Esta tomada de consciência do potencial impacto das nanotecnologias foi posteriormente mobilizada por meio da aplicação das técnicas do Teatro Fórum (Boal, 1977), tendo os grupos transformado as suas preocupações éticas e sociais em performances teatrais que apresentaram ao outro grupo. Após a performance, havia um período de discussão que potenciava uma troca de papéis para a reencenação da peça, consoante as diferentes abordagens de cada grupo.

Diferentes performances foram levadas a cabo: o primeiro grupo encenou uma discussão no seio de um Comité de Ética sobre a utilização de nanotecnologias na terapia do cancro; o segundo grupo apresentou um sketch no qual uma personagem, desempenhando simultaneamente o papel de cientista e de criança, oferecia diferentes prendas, representadas por distintas aplicações de nanotecnologias (área militar, medicina e consumo) a várias pessoas, a quem competia rebater as ofertas mediante argumentos que aludiam a alternativas não tecnológicas de estar no mundo; o terceiro grupo apresentou um sketch baseado no programa televisivo "Prós e Contras"4, configurando um painel de oradores oriundos de

${ }^{4}$ Programa televisivo português, do canal RTP1, que debate semanalmente um assunto controverso e atual e que conta com um elenco de convidados com posições distintas sobre o tema em discussão. 
diversas áreas (militar, científica e ambiental) que enalteciam os benefícios da tecnologia e que iam sendo interrompidos por membros da audiência que refutavam alguns dos argumentos otimistas apresentados; o quarto grupo preparou uma performance em que, através da recriação dos mitos de Pandora e Prometeu, ilustrou o duplo carácter de perigo e de promessa das nanotecnologias.

Estas performances transformaram as diferentes conceções de nanotecnologias em processos dramatúrgicos que permitiram a articulação de conhecimentos sobre nanotecnologia suportada pelo formato aberto e livre da performance.

\section{A performatividade dos grupos de discussão}

Tendo como pano de fundo estes exercícios de participação pública em Ciência e Tecnologia, como refletir acerca do sujeito participativo sob o prisma da performatividade?

Em primeiro lugar, a equipa de investigação reconheceu a dimensão política do desenho e condução de exercícios participativos. A metodologia das Ciências Sociais foi considerada uma forma de política ontológica (Mol, 1999). O que estava em causa não era um processo de identificação de enunciados éticos pré-estabelecidos acerca das nanotecnologias, mas sim a "construção" de um sujeito participativo através de dispositivos que permitissem a adoção de um ethos antecipatório, uma "nanoética" (Carvalho; Nunes, 2013).

A emergência de preocupações acerca dos potenciais efeitos das nanotecnologias foi mediada através do quotidiano dos participantes, segundo a pedagogia do oprimido de Paulo Freire. O mesmo se passou em relação à preparação das performances, procurando-se um processo interativo de produção do conhecimento, uma "discência" (Freire, 1970) em que os organizadores do exercício participativo (sociólogos) eram convidados a entrar na vida dos participantes através de diferentes possibilidades de um futuro diferente, condicionado por novas tecnologias. 
A abordagem dialogista de Freire permitiu uma simetria epistemológica entre organizadores e participantes.

Os sujeitos tornaram-se cidadãos preocupados com nanotecnologias por fazerem parte do agenciamento participativo, uma rede sociotécnica composta por metodologias, novos conhecimentos, um espaço físico e expectativas em relação ao que deveriam produzir. As reflexões de Foucault sobre disciplina elucidam acerca da fabricação institucional da subjetividade (Foucault, 1975). Neste caso, o laboratório de Ciências Sociais transformou cidadãos sem conhecimentos sobre nanotecnologias em sujeitos com a capacidade de articular preocupações éticas e sociais sobre estas tecnologias, associando-as à sua experiência quotidiana (seguindo a metodologia freireana) e ilustrando-as através dos recursos performativos desenvolvidos por Boal. Dessa forma, reconhece-se que a integração dos indivíduos no agenciamento participativo permite a enunciação de preocupações éticas e a ação coletiva, através de formas de conscientização sobre o complexo científico/social.

Para que o agenciamento produzisse subjetividades participativas, os investigadores projetaram slides com informação sobre nanotecnologias; interpelaram os participantes sobre os potenciais impactos nas suas vidas, "performando" as suas identidades através de atos discursivos (Butler, 1990; Althusser, 2008); explicaram como deveriam ser organizadas as apresentações finais; agruparam os indivíduos em grupos com títulos específicos, contribuindo para a formação de um espírito coletivo que potenciasse a criação de equipas (Goffman, 1993); anotaram as principais ideias resultantes das discussões em grupo, lendo-as no final, contribuindo para a sedimentação e memorização de representações sobre nanotecnologias. Estas diferentes formas de agência elucidam acerca do papel da equipa de investigação que, ao "facilitar" o exercício, permitiu a emergência do sujeito participativo, através de escolhas que contribuíram para agenciamentos específicos.

Estes exercícios revelaram-se interessantes para refletir acerca da performatividade dos dispositivos participativos, permitindo abordar 
diferentes formas de distribuição de agência. Os ESCT têm salientado a importância em reconhecer o papel da agência não humana, material (Pickering, 1995), questionando uma abordagem discursiva e antropocêntrica das práticas científicas e propondo interpretações pós-humanistas dos agenciamentos sociotécnicos (Latour, 2005).

No que diz respeito aos grupos de discussão, numa primeira análise, poderíamos atribuir agência exclusivamente à intencionalidade metodológica da equipa de investigação, que subjetiva os participantes, tornando-os sujeitos participativos. Porém, é mais correto interpretar o processo de subjetivação como uma dança de agência (Pickering, 1995) entre diversas entidades cujas fronteiras ontológicas são fluidificadas pelas diferentes interações em causa. Em primeiro lugar, os participantes não são sujeitos passivos. A abordagem metodológica, que valoriza a simetrização epistemológica num espaço partilhado, evita uma conceção "bancária" (Freire, 1970) dos sujeitos. Estes, para além de contribuírem com os seus conhecimentos particulares, também negoceiam com a equipa de investigação através de: discussões em relação à forma como conduzir o exercício, envolvendo negociações acerca do formato final e a sua correspondência com as expectativas dos organizadores; pedidos de determinados materiais à equipa de investigação para a construção de artefactos que auxiliam na apresentação da performance e que contribuem para um exercício de política ontológica, de criação de mundos possíveis; pedidos de não interferência da equipa de investigação durante o desenho da performance.

Esta distribuição da agência não se esgota nas danças ontológicas entre equipa de investigação e participantes. Seguindo as abordagens póshumanistas da interpretação da prática científica, não podemos ignorar a importância da agência material na emergência do cidadão participativo. Que actantes são estes que subjetivam os cidadãos e como são levados a cabo estes processos de subjetivação distribuída?

Um mapeamento provisório dos actantes incluiria slides projetados explicando o que são as nanotecnologias, quais as suas aplicações e o 
seu futuro; materiais (como canetas, caixas de cartão, papéis) que são recrutados para levar a cabo as performances e que transportam formas e sentidos possíveis para uma imaginação sobre nanotecnologias; emails que explicam aos participantes os objetivos do projeto e o que deles é esperado; acervo burocrático (como recibos), revestido de simbolismo institucional, recentrando os indivíduos enquanto participantes num laboratório de Ciências Sociais; telemóveis que são recrutados para ilustrar a disseminação contemporânea das tecnologias. Estes exemplos não esgotam as possibilidades de identificação dos elementos materiais que emergem nos processos de subjetivação. Segundo Barad (2003), estamos perante formas de performatividade material e discursiva que dizem respeito tanto às lutas de agência entre humanos (investigadores e participantes) como entre os humanos e não humanos, reconhecendo-se a heterogeneidade do agenciamento participativo.

\section{A ontologia do sujeito participativo}

Analisaram-se várias vertentes relacionadas com a subjetivação do sujeito participativo. No entanto, como podemos refletir acerca das ontologias do sujeito que emergiram? Que tipo de sujeito participativo é este? Que tipo de "equipamentos" são desenvolvidos e como é que estes podem ser mobilizados para a esfera da vida quotidiana?

As reflexões de Foucault (2006) acerca das tecnologias do sujeito permitem-nos encará-las como um equipamento ético que pode ser aplicado nas mais variadas circunstâncias do dia a dia. No caso dos grupos de discussão sobre nanotecnologias, como podemos refletir acerca dos conceitos de equipamento e habilitação, já que o sujeito transporta uma vontade ética e política para transformar o agenciamento em que se insere? De que forma é que o exercício participativo permitiu a emergência do que Freire designava como o "sujeito conscientizado" (Freire, 1970) que, através de uma abordagem dialogista e simétrica à alfabetização, desenvolve o seu intelecto e ação em função da sua situação no mundo, que visa transformar? 
Os grupos de discussão permitiram o desenvolvimento de preocupações éticas e sociais acerca de uma tecnologia cujas aplicações mais promissoras estão ainda em fase experimental. A conscientização é voltada para o futuro, e os participantes articulam as suas preocupações em função das suas situações específicas no mundo - ativistas, membros de organizações de pacientes ou defensores de terapias alternativas -, agindo como membros situados de determinados coletivos. Nesse sentido, as políticas de habilitação devem ser encaradas como permitindo uma conscientização acerca de um mundo marcado pela proliferação de um novo tipo de tecnologia. A relação do sujeito com esse mundo é mediada por diferentes aspetos: i) capacidades retóricas e performativas; ii) experiência anterior com tecnologias; iii) o caráter vinculativo do futuro imaginado; iv) a manutenção da memória da experiência participativa, permitindo a continuidade da conscientização com nanotecnologias; v) a disponibilidade para transportar esta experiência para as interações quotidianas, permitindo que outros cidadãos se familiarizem com alguns dos aspetos em causa. Consequentemente, se as políticas de habilitação permitem a transformação dos agenciamentos nos quais se inserem os indivíduos, como devemos encarar a relação entre os grupos de discussão, participação e transformação social, já que as tecnologias em questão fazem parte do futuro?

A transformação de agenciamentos é operada através de dois vetores. Por um lado, o espaço de participação foi desenhado de forma a ser influenciado pela agência dos participantes e pelo seu quotidiano - ao invés de ser um dispositivo disciplinar com um foco de agência unívoco, ele permite as mais diversas interações, que transformam o desenho da "instituição participativa" e os resultados da ação. Por outro lado, através da conscientização dos participantes espera-se que estes se possam envolver ativamente nos processos de transformação do futuro, marcado pelo papel das nanotecnologias em diversas áreas como a medicina, o ambiente, o consumo ou o armamento. Os planos de ação para o futuro, ao invés de terem sido definidos pelo espaço participativo como uma forma de colonização da agência política dos indivíduos, ficam a cargo dos cidadãos 
e das suas escolhas, em função do equipamento ético que emergiu com o agenciamento.

\section{Conselheiros de Saúde e Cursos de Educação Permanente}

O segundo estudo de caso diz respeito aos Conselhos Municipais de Saúde em Belo Horizonte (CMSBH) e à implementação de Cursos de Educação Permanente para Conselheiros (CEP). A sua análise decorreu em 2008, no âmbito do projeto ResIST ${ }^{5}$, que visava compreender o modo como a Ciência e a Tecnologia contribuem para a mitigação ou aprofundamento das desigualdades sociais. No âmbito deste projeto identificaram-se e analisaramse estruturas de prestação de contas, responsabilização e participação que incorporassem necessidades de populações desfavorecidas. Foram realizadas entrevistas semiestruturadas a conselheiros de saúde, acompanhadas de análise documental de legislação do Sistema Único de Saúde (SUS) e do histórico das atas de reuniões dos Conselhos de Saúde de Belo Horizonte.

Associados a um processo alargado de participação pública no âmbito do debate constitucional brasileiro na década de 1980, os Conselhos de Saúde são espaços institucionalizados de participação e de responsabilidade coletiva entre os múltiplos atores intervenientes no SUS. Estes assumemse como espaço de construção da cidadania através de processos de participação e deliberação na construção da política brasileira de saúde. A sua arquitetura institucional baseia-se numa composição paritária entre representantes da sociedade civil (50\%), dos órgãos institucionais de gestão e dos trabalhadores na área da saúde (25\% cada).

No seguimento da avaliação de 20 anos de atuação do Conselho sobre a qualidade da participação dos conselheiros, o CMSBH criou cursos de capacitação, também designados de cursos de educação permanente, dirigidos aos conselheiros e com o intuito de promover uma participação mais qualificada. Os CEP recorrem à pedagogia dialogista proposta por Paulo

${ }^{5}$ ResIST - Researching Inequality Through Science and Technology (2006-2009), coordenado por João Arriscado Nunes, do Centro de Estudos Sociais da Universidade de Coimbra e financiado pela Comissão Europeia. 
Freire (1970) para habilitar os conselheiros à participação, visando ajustar discrepâncias entre conselheiros decorrentes de diferentes habilitações literárias e experiências de participação, que lhes conferem distintas disposições e capacidades para a sua ação no Conselho (Gerschman, 2004). Neste artigo, analisamos a necessidade da criação dos CEP enquanto exemplo ilustrativo de como a criação de dispositivos de participação implica um conjunto de disposições e de formas de subjetivação. Os excertos de entrevistas a conselheiros do CMSBH ilustram a sua experiência prática com dificuldades associadas à participação nos Conselhos, assim como o papel dos CEP na promoção de disposições mais qualificadas. O primeiro excerto permite um enquadramento do problema em questão:

A saúde acontece na comissão local. [...] O Conselho tem que refletir a realidade das comissões locais porque é lá que nós temos a promoção da saúde, as políticas de prevenção e recuperação. Para nós é importante [...] aproximar as pautas e as discussões do Conselho Municipal, dos Conselhos Distritais e das comissões locais da realidade. O grande problema que desmotiva o conselheiro é ver demandas e necessidades numa unidade de saúde e não ver isso refletido nas discussões, nas pautas do Conselho, das comissões locais, dos Conselhos Distritais, e isso para nós é fundamental. [...] É essa a visão do conselheiro: eu estou participando no Conselho local, mas o que estão discutindo? É o que eu encontro nas filas da unidade? É o que a gente acha dos problemas de infraestruturas, de gestão, de recursos humanos, [...]? Essa aproximação é para nós uma questão sine qua non, ensinar o conselheiro a ter essa aferição. [...] Nós queremos que o Conselho tenha essa interlocução, que cada conselheiro seja um sujeito no processo de transformação [...]! [...] O conselheiro ser um agente que vai mudar a realidade. Então nós temos uma política de educação permanente [...] que está dando ferramentas e instrumentos [...] para que o conselheiro, na sua atuação diária, tenha um protagonismo de sujeito, na própria prática, na participação da reunião do Conselho, nas conferências de saúde, eles possam ter proveito disso, de potencializar o que eles querem, nós não queremos mudar o conselheiro! Nós queremos as características do conselheiro, as suas reivindicações, as suas necessidades, mas potencializadas! Da forma de participar, tendo, por exemplo, um planejamento estratégico do próprio Conselho. Porque nós sabemos, um conselheiro pode querer, por exemplo, mais médico na unidade, o outro pode querer mais medicamento, como é que eles agendam isso? Como é que as duas demandas não se debatem entre si, não se digladiam entre si? Mas que se potencializem? E dentro de um planejamento que agenda é que vem primeiro? [...] isso é a gente ensinar a grupacidade, você ter uma noção de grupo onde os saberes 
daquele grupo, as necessidades, não digladiam entre si, isso é muito importante para o conselheiro, se não o próprio Conselho fica brigando entre si, os conselheiros, às vezes usuário com trabalhador, trabalhador com trabalhador, usuário com usuário, e não tem esse direcionamento de como suprir as necessidades existentes. Como potencializar a capacidade do Conselho de buscar essa solução em conjunto? (Entrevista com Conselheiro, trabalhador na área da saúde, outubro de 2008).

Neste longo excerto, salienta-se a dificuldade sentida pelos conselheiros em colocar em pauta no Conselho os problemas que encontram nas unidades de saúde e as reivindicações de que são porta-vozes. Como refere o entrevistado, sem esta "aferição", há uma impossibilidade de o conselheiro constituir-se como sujeito participativo. Ao não se constituir como "sujeito no processo de transformação e resolução dos problemas", a própria função do Conselho é condicionada, já que este é um dispositivo de "interlocução" entre sujeitos e necessidades sentidas, almejando uma gestão participada da política de saúde. Dessa forma, é fundamental levar a cabo duas reflexões: em primeiro lugar, sobre as causas dessa dificuldade, que julgamos terem origem na incapacidade de transportar e traduzir esses problemas num "planejamento estratégico" no dispositivo dos Conselhos de saúde; em segundo lugar, acerca das condições que permitem realizar com sucesso esse transporte e tradução - de acordo com o excerto da entrevista, estas estão associadas à posse de "ferramentas e instrumentos" que sustentam e melhoram a capacidade participativa dos conselheiros.

Analisemos a capacidade dos sujeitos em transportar e enquadrar no dispositivo de discussão e deliberação as entidades consideradas relevantes e inteligíveis, ou seja, enquanto entidades que "contam". O sucesso desta operação depende da capacidade dos conselheiros, enquanto porta-vozes de posições, exigências e reivindicações, de disporem do equipamento entendido como recursos técnicos, epistémicos, expressivos e materiais - de modo a permitir-lhes fazer a sua tradução em termos considerados admissíveis no espaço do Conselho. São estas ferramentas e instrumentos que constituem o equipamento de medição e avaliação, que suporta não só a "aferição" do conselheiro, previamente referida, mas também a capacidade de tornar os temas admissíveis e, assim, formas legítimas de participação. 
As condições de admissibilidade são suportadas por um trabalho de tradução (Callon, 1986; Law, 1987) que o conselheiro leva a cabo, consistindo na criação de um ator-rede constituído por entidades humanas e não humanas e interesses heterogéneos alinhados de forma a dar corpo a argumentos e reivindicações. A tradução articula entidades do quotidiano e do agenciamento burocrático e sociotécnico do SUS, e ao fazê-lo adquire autoridade técnica, política e epistémica. Dessa forma, a ação participativa emerge não como propriedade do indivíduo, mas como uma ação distribuída (Callon, 2008) que pressupõe a mobilização de entidades e recursos que o habilitam a agir em conformidade com o dispositivo participativo. A ação participativa não tem origem exclusiva no sujeito, mas sim nos equipamentos que o autorizam e habilitam a agir enquanto sujeito político, neste caso, como conselheiro de saúde. A constituição do dispositivo implica, dessa forma, a constituição de um sujeito participativo e das disposições adequadas à admissibilidade/legitimidade da participação.

São duas as dimensões que se cruzam. Por um lado, a adoção dos procedimentos burocráticos, técnicos e institucionais do SUS e do Conselho e, por outro lado, a mobilização de informação sobre as realidades locais pelos conselheiros. Só assim o conselheiro se torna competente para traduzir as suas reivindicações de modo a serem inteligíveis, admissíveis e legítimas enquanto argumentos que contam para a discussão. Sem essa capacidade, a sua participação será inócua, pois não conseguirá traduzir os problemas e necessidades daqueles que representa.

Em primeiro lugar, está em causa a capacidade dos conselheiros em mobilizarem os princípios que estruturam o dispositivo do Conselho enquanto parte do agenciamento legislativo e técnico do SUS, incluindo os enunciados do projeto de reforma sanitária, na sua dimensão política e epistémica, todo o quadro constitucional e legislativo que lhe dá forma e as leis de financiamento, orçamentação e alocação de recursos públicos. Em segundo lugar, está em causa a sua capacidade para traduzir os problemas locais em reivindicações políticas, integradas na orçamentação e alocação 
de recursos associadas ao exercício de governação da saúde efetivado pelos Conselhos:

A nossa função é a de fazer um elo, porque o SUS não tem razão de ser, se não existirem médicos, trabalhadores e usuários! [...] É evidente que nós vamos ter momentos em que vamos criticar o trabalhador, o gestor, em que nós seremos criticados por eles, mas dentro de uma política de construção [...]. O nosso objetivo é formatar essa política, visando o crescimento da saúde, ver onde tem falha e, de comum acordo, tentar aparar essas falhas. A gente tenta passar que a saúde é um conjunto! [...] O nosso objetivo é ver onde é que tem a falha, trazer sugestão e em conjunto construir uma solução. [...] E só se consegue isso se você conhecer o sistema. Então, essa capacitação traz para nós o conhecimento do sistema, os melindres, os conhecimentos das leis, abre os nossos horizontes para a gente ver que o enfoque de saúde passa por ações, entendimentos, planejamento, por uma gestão e uma ação mais intrínseca entre gestor, trabalhador e usuário. Porque se não houver a participação de um dos lados, o sistema vai ficar amarrado. Então é necessária essa participação em conjunto, essa união de forças, para solidificar o sistema (Entrevista com Conselheiro Usuário, outubro de 2008).

O programa de educação permanente visa promover a aquisição do "equipamento" necessário à participação dos conselheiros, conferindo-lhes as disposições associadas ao dispositivo específico do Conselho. Com base no excerto citado, a capacitação confere "o conhecimento do sistema, das leis e os seus melindres", que fortalece a capacidade do conselheiro em identificar as "falhas" do SUS, as situações problemáticas da realidade de que é porta-voz, transpondo-as para o dispositivo do Conselho - classificando-as, ordenando-as e colocando-as em ação. Dessa forma, é possível hierarquizar e priorizar ações e planeamentos inteligíveis para "construir soluções" que se refletem em políticas concretas de gestão.

O papel desempenhado pelo conselheiro, enquanto sujeito de transformação da realidade, é uma performance que tem lugar apenas no quadro do CMSBH. Só dentro do dispositivo do Conselho é que o papel do conselheiro é dotado de sentido. Assim, apenas ao entrar no dispositivo do Conselho, e munido das competências e ferramentas necessárias, o conselheiro ganha capacidades e possibilidades de ação transformadoras da realidade. $\mathrm{O}$ cidadão participativo não emerge espontaneamente, mas através do dispositivo 
que o habilita à participação. Habilitar à participação significa facultar os equipamentos necessários à transformação daquilo que são exigências e reivindicações em identificação e definição de problemas, inventariação e hierarquização de situações, definição de cursos de ação, mobilização de recursos, monitorização e avaliação de políticas.

Devemos analisar o fenómeno participativo nos Conselhos enquanto performance não apenas do sujeito conselheiro, mas do dispositivo Conselho de Saúde enquanto espaço de interlocução dos distintos atores que participam no SUS e que, através do diálogo, levam a cabo a Saúde Coletiva como projeto político-epistémico. Inspirados por uma leitura póshumanista dos ESCT (Barad, 2003), propomos uma análise do fenómeno participativo que considera que sujeito (conselheiro), objeto (saúde coletiva) e dispositivos (Conselhos de Saúde) resultam de um enactment (Mol, 1999) em que estes fenómenos se constituem relacionalmente.

Este enactment está patente nos dois excertos citados, que salientam o papel de "grupacidade" e da "função de elo" entre os distintos grupos que compõem o SUS (usuários, trabalhadores e gestores), apresentando o Conselho enquanto um coletivo heterogéneo que permite a produção da saúde na interlocução entre os diferentes conselheiros. A constituição destes diferentes grupos no Conselho enquanto coletivo assenta nesta noção veiculada de "grupacidade", que comunica e age coletivamente com vista a "formatar [uma] política" para construir um "comum acordo", em que "a saúde é um conjunto" que resulta da construção do coletivo enquanto tal, visando o "crescimento da saúde". A função mencionada de "fazer um elo" entre os atores, num processo por vezes de convergência e de consenso, mas também de conflito e de crítica, é central, dada a conceção ampla de saúde relacionada com a criação do SUS, associada a um processo mais geral de democratização da saúde pública. 


\section{Conclusão}

As reflexões veiculadas por estes dois estudos de caso sugerem que os dispositivos de participação - enquanto formas institucionalizadas e contínuas de influência nas políticas de saúde ou exercícios temporalmente limitados para a identificação de imaginários sociotécnicos sobre nanotecnologias levam à emergência de um "cidadão participativo", constituindo mecanismos de subjetivação. Através do contato com os agenciamentos participativos, os atores emergem enquanto sujeitos políticos e desenvolvem uma consciência coletiva e situada acerca do "objeto" da participação. Reconhecendo a profunda dimensão política do fenómeno participativo, e da subjetivação a ele associada, surgem várias questões que iremos abordar de seguida.

Estes procedimentos constituem-se como formas assimétricas de governar os indivíduos. Ao equipar o sujeito com os instrumentos materiais e epistemológicos necessários para a "participação", constitui-se um duplo governo da sua subjetividade: primeiro, ela é modificada em função da adaptação ao dispositivo; segundo, dessa subjetividade "equipada" é extraída informação sobre as suas preocupações e anseios que, depois, é canalizada para as instituições de governação.

A participação é um mecanismo de construção do cidadão. Por um lado, canaliza a participação para formas "legítimas" ou "legais" de intervenção no espaço público e, por outro, reifica a distinção entre formas legítimas e ilegítimas (ou "desajustadas") de participação. Dessa forma, movimentos de protesto são frequentemente constituídos como tentativas ilegítimas (ou não convencionais) de participação política e, como tal, disruptivas da ordem pública. Tal deve-se ao facto de este tipo de ação aparecer como "ilegível" para a cultura dominante da decisão técnicopolítica, não reconhecendo como participação fenómenos que escapam aos formatos institucionalizados e estruturados de forma hierárquica. Não é coincidência que os exercícios participativos, promovidos em larga escala pela Comissão Europeia, sejam acompanhados por formas de delegação de competências políticas e legais em mecanismos supranacionais, muitas 
vezes desprovidos de verdadeira transparência, podendo, nesse sentido, servir apenas para a legitimação de políticas previamente determinadas e desligadas da vontade popular (Carvalho; Nunes, 2014).

Os exercícios participativos devem permitir uma copresença radical e simétrica entre cidadãos, políticos, peritos e moderadores, sendo capazes de incorporar formas mais espontâneas e "leigas" de participação, com um caráter vinculativo e não meramente simbólico e legitimador do status quo. Este processo deve incluir o desenvolvimento de formas partilhadas de produção de sentidos possíveis do mundo, num processo de "pôr em comum" (Latour, 2014). De facto, em exercícios participativos que procuram a criação de subjetividades "situadas" e de cidadanias "informadas", é patente a tensão entre a necessidade de permitir a emergência de uma conceção coerente da realidade e o imperativo de que esta visão do mundo emerja em conformidade com a heterogeneidade de experiências subjetivas dos sujeitos envolvidos. A emergência destas subjetividades ocorre através do "fenómeno participativo". Isto significa que a fabricação de uma conceção situada e comum de um problema político (o acesso à saúde ou implicações éticas de nanotecnologias) é contaminada pelos discursos, materialidades e técnicas constituintes do próprio dispositivo participativo.

Esta contaminação desvela as tensões entre regulação/emancipação (Santos, 1995) e reabilitação/habilitação (Callon, 2008) inerentes a estes dispositivos e ao processo de aquisição do equipamento que predispõe à participação. A assunção de uma simetria radical que permita a emergência de múltiplas epistemologias e estilos metodológicos levanta a questão dos processos de tradução necessários para permitir que o sujeito participativo consiga, por um lado, "inscrever" a sua ação política de forma vinculativa (sendo incorporada nos processos de decisão), mas também "livre", no que concerne à forma (como uma história de vida, uma peça de teatro, e outros exemplos artísticos, performativos e não verbais).

Apesar das complexidades e dificuldades associadas aos procedimentos participativos, estes são uma forte alternativa aos sistemas de democracia representativa contemporâneos que promovem uma clivagem entre cidadãos, 
políticos e peritos, associada a diferenciais epistemológicos. Um sistema político que ambicione generalizar os procedimentos participativos tem de assentar no reconhecimento da diversidade de ontologias do sujeito e na possibilidade de existirem diferentes ontoepistemologias (Barad, 2003) do mundo, substanciadas por diversas disposições dos indivíduos e coletivos.

Este artigo procura contribuir para uma discussão acerca das complexas relações entre dispositivos de participação, metodologias, subjetividades e políticas ontológicas, reconhecendo que os problemas das democracias contemporâneas não terminam onde começa a participação. De facto, esta suscita uma série de novas problemáticas a que só a prática, a experimentação e a colaboração poderão responder, exigindo não só uma reinvenção da democracia, mas também a revisão dos dispositivos e metodologias de participação.

João Arriscado Nunes é Professor Catedrático de Sociologia da Faculdade de Economia da Universidade de Coimbra, cocoordenador do Programa de Doutoramento "Governação, Conhecimento e Inovação" e Investigador do Centro de Estudos Sociais.

Đjan@ces.uc.pt

Daniel Neves da Costa é Doutor em Sociologia e Investigador de Pós-Doutoramento no Centro de Estudos Sociais da Universidade de Coimbra no Grupo de Estudos sobre Ciência, Economia e Sociedade (NECES).

$\fallingdotseq$ danielneves@ces.uc.pt

António Carvalho é Doutor em Sociologia pela Universidade de Exeter, Reino Unido, bolseiro de pós-doutoramento no Instituto de Higiene e Medicina Tropical da Universidade Nova de Lisboa e investigador associado do Centro de Estudos Sociais da Universidade de Coimbra.

ఏamcarvalho@ces.uc.pt

Ana Raquel Matos é Doutora em Sociologia e Investigadora do Centro de Estudos Sociais e membro do Núcleo de Estudos Sobre Ciência, Economia e Sociedade (NECES). Realiza pós-doutoramento financiado pela Fundação para a Ciência e a Tecnologia (Refa SFRH/ BPD/94178/2013).

”’ amatos@ces.uc.pt 


\section{Referências}

1. ALTHUSSER, Louis. On Ideology. Nova lorque: Verso, 2008.

2. BARAD, Karen. Posthumanist Performativity: Toward an Understanding of How Matter Comes to Matter. Signs: Journal of Women in Culture and Society, v. 28, n. 3, p. 801-31, primavera de 2003.

3. BOAL, Augusto. Teatro do oprimido e outras poéticas políticas. Rio de Janeiro: Civilização Brasileira, 1977.

4. BREY, Philip. Anticipatory Ethics for Emerging Technologies. Nanoethics, v. 6, n. 1, p. 1-13, abr. 2012.

5. BROCK, David. Network Effects: Communities, Devices, and Disciplines. Metascience, Kensington, v. 23, n. 1, p. 113-6, mar. 2014.

6. BUTLER, Judith. Gender Trouble. Londres: Routledge, 1990.

7. CALLON, Michel. Some Elements of a Sociology of Translation: Domestication of the Scallops and the Fishermen of St. Brieuc Bay. In: LAW, John (Org.). Power, Action and Belief: A New Sociology of Knowledge? Londres: Routledge, 1986. p. 196-223.

8. CALLON, Michel. The laws of the Markets. Oxford: Blackwell, 1998.

9. CALLON, Michel. What Does it Mean to Say that Economics is Performative? CSI Working Papers Series, n. 005, 2006. Disponível em: <http://www.csi. ensmp.fr/Items/WorkingPapers/Download/DLWP.php?wp=WP_CSI_005.pdf $>$.

10. CALLON, Michel. Economic Markets and the Rise of Interactive Agencements: From Prosthetic Agencies to Habilitated Agencies. In: PINCH, Trevor; SWEDBERG, Richard (Orgs.). Living in a Material World. Cambridge: The MIT Press, 2008, p. 29-56.

11. CALLON, Michel; LASCOUMES, Pierre e BARTHE, Yannick. Acting in an Uncertain World: an Essay on Technical Democracy. Cambridge: MIT Press, 2009.

12. CALLON, Michel; MUNIESA, Fabian. Les marchés économiques comme dispositifs collectifs de calcul. Réseaux, v. 21, n. 122, p. 189-233, 2003.

13. CARVALHO, António. Subjectivity, Ecology and Meditation: Performing Interconnectedness. Subjectivity, v. 7, n. 2, p. 131-50, jul. 2014.

14. CARVALHO, António. Ecologies of the Self in Practice - Meditation, Affect and Ecosophy. Geografiska Annaler: Series B, Human Geography, v. 99, n. 2, p. 207-22, jul. 2017.

15. CARVALHO, António; NUNES, João Arriscado. Intervenção e envolvimento público em Ciência e Tecnologia: o caso das nanotecnologias. Estudos de Sociologia, v. 19, n. 37, p. 431-49, jul./dez. 2014. 
16. CARVALHO, António; NUNES, João Arriscado. Technology, Methodology and Intervention: Performing Nanoethics in Portugal. NanoEthics, v. 7, n. 2, p. 14960, jun. 2013.

17. EBBESEN, Mette et al. Ethics in Nanotechnology: Starting from Scratch? Bulletin of Science, Technology \& Society, v. 26, n. 6, p.451-62, dez. 2006.

18. FOUCAULT, Michel. Surveiller et punir - Naissance de la prison. Paris: Gallimard, 1975.

19. FOUCAULT, Michel. Technologies of the Self. In: MARTIN, Luther; GUTMAN, Huck; HUTTON, Patrick (Orgs.). Technologies of the Self. A Seminar with Michel Foucault. Amherst: The University of Massachusetts Press, 1988. p. 16-49.

20. FOUCAULT, Michel. Le sujet et le pouvoir. In: FOUCAULT, Michel. Dits et écrits II, 1976-1988. Paris: Gallimard, 2001. p. 1041-62.

21. FOUCAULT, Michel. The Hermeneutics of the Subject - Lectures at the Collège de France 1981-1982. Nova lorque: Picador, 2006.

22. FREIRE, Paulo. Pedagogia do oprimido. Rio de Janeiro: Paz e Terra, 1970.

23. FREIRE, Paulo. Pedagogia da autonomia. Rio de Janeiro: Paz e Terra, 2008.

24. GERSCHMAN, Sílvia. Conselhos Municipais de Saúde: atuação e representação das comunidades populares. Cadernos de Saúde Pública, v. 20, n. 6, p. 1670-81, nov./dez. 2004.

25. GOFFMAN, Erving. A apresentação do Eu na vida de todos os dias. Lisboa: Relógio D'Água, 1993.

26. HARDT, Michael; NEGRI, Antonio. Empire. Cambridge: Harvard University Press, 2001.

27. HUTCHINS, Edwin. Cognition in the Wild. Cambridge: The MIT Press, 1994.

28. JASANOFF, Sheila. Designs on Nature: Science and Democracy in Europe and the United States. Princeton: Princeton University Press, 2005.

29. JASANOFF, Sheila; KIM, Sang-Hyun. Containing the Atom: Sociotechnical Imaginaries and Nuclear Power in the United States and South Korea. Minerva, v. 47, n. 2, p. 119-46, jun. 2009.

30. JENSEN, Casper Bruun et al. New ontologies? Reflections on some Recent 'Turns' in STS, Anthropology and Philosophy. Social Anthropology, v. 25, n. 4, p. 525-45, nov. 2017.

31. LATOUR, Bruno. Reassembling the Social: an Introduction to Actor-NetworkTheory. Nova Iorque: Oxford University Press, 2005.

32. LATOUR, Bruno. Another Way to Compose the Common World. HAU: Journal of Ethnographic Theory, v. 4, n. 1, verão 2014.

33. LAW, John. Technology and Heterogeneous Engineering: The case of the Portuguese Expansion. In: BJIKER, Wiebe; HUGHES, Thomas; PINCH, Trevor 
(Orgs.). The Social Construction of Technical Systems: New Directions in the Sociology and History of Technology. Cambridge: MIT Press, 1987. p. 111-34.

34. LAW, John. After Method - Mess in Social Science Research. Londres: Routledge, 2004.

35. LAW, John; HASSARD, John (orgs.). Actor Network Theory and after. Oxford: Blackwell, 1999.

36. MOL, Annemarie. Ontological Politics. A Word and Some Questions. In: LAW, John; HASSARD, John (Org.). Actor Network Theory and After. Oxford: Blackwell, 1999. p. 74-90.

37. NUNES, João Arriscado et al. Policy Report: New Accountability Systems, Experimental Initiatives and Inequalities in Public Policy and Health Policy Domains. Coimbra: Centro de Estudos Sociais, 2009.

38. PICKERING, Andrew. The Mangle of Practice - Time, Agency \& Science. Chicago: Chicago University Press, 1995.

39. RABINOW, Paul. Anthropos Today: Reflections on Modern Equipment. Princeton: Princeton University Press, 2009.

40. ROWE, Gene; FREWER, Lynn. Public Participation Methods: a Framework for Evaluation. Science, Technology \& Human Values, v. 30, n. 2, p. 3-29, inverno 2000.

41. ROWE, Paul; FREWER, Lynn. A Typology of Public Engagement Mechanisms. Science, Technology \& Human Values, v. 30, n. 2, p. 251-90, abr. 2005.

42. SANTOS, Boaventura de Sousa. Toward a New Common Sense. Law, Science and Politics in the Paradigmatic Transition. Nova lorque: Routledge, 1995.

43. SANTOS, Boaventura de Sousa. A crítica da governação neoliberal: O Fórum Social Mundial como política e legalidade cosmopolita subalterna. Revista Crítica de Ciências Sociais, v. 72, p. 7-44, out. 2005.

44. SANTOS PEREIRA, Tiago; CARVALHO, António; FONSECA, Paulo. Imaginaries of nuclear energy in the Portuguese parliament: Between promise, risk, and democracy. Public Understanding of Science, v. 26, n. 3, p. 289-306, abr. 2017.

45. SWEENEY, Aldrin et al. The Promises and Perils of Nanoscience and Nanotechnology: Exploring Emerging Social and Ethical Issues. Bulletin of Science, Technology and Society, v. 23, n. 4, p. 236-45, ago. 2003.

46. WOOLGAR, Steve; LEZAUN, Javier. The Wrong Bin Bag: A Turn to Ontology in Science and Technology Studies? Social studies of science, v. 43, n. 3, p. 32140, jun. 2013.

47. WYNNE, Brian et al. Taking European Society Seriously. Luxembourg: Office for Official Publications of the European Communities, 2007. Disponível em: <http://ec.europa.eu/research/science-society/document_library/pdf_06/ european-knowledge-society_en.pdf $>$. 